\title{
Reducing of industrial atmospheric emissions using electrocyclone
}

\author{
Anatolii Titov ${ }^{\mathrm{a}^{*}}$, John Shrimpton ${ }^{\mathrm{b}}$, \\ Cheng Shao ${ }^{c}$, Zhuohan $\mathrm{Li}^{\mathrm{c}}$ \\ ${ }^{a}$ Ural Federal University, 19 Mira st., Ekaterinburg, 620002, Russia \\ ${ }^{b}$ University of Southampton, University Road, \\ Southampton, SO17 1BJ, United Kingdom \\ 'Dalian University of Technology, No. 2 Linggong Road, \\ Ganjingzi District, Dalian City, Liaoning Province, 116024, China \\ email:a.g.titov@urfu.ru
}

\begin{abstract}
The article is focused on capturing process-related dust at industrial enterprises (in chemical, metallurgical and energy industries). An electrocyclone can be recommended for the purification of gases emitted into the atmosphere from particulates, such as sodium percarbonate (efficiency $97.5 \%$ - 99.9\%), iron-vanadium concentrate $(98.0 \%-99.9 \%)$, fly ash $(99.0 \%$ - 99.9\%). However, the fumes from copper-smelting furnaces cannot be purified with high efficiency (less than 50-60\%) because of their properties. Using electrocyclone will reduce the amount of aerosol emissions, and in some cases, let the emission reach the values set by standards.
\end{abstract}

Keywords: gas purification; electrocyclone; cyclone; electrostatic precipitator

Received: 16.10.2020. Accepted: 07.12.2020. Published:30.12.2020.

(C) Anatolii Titov, John Shrimpton, Cheng Shao, Zhuohan Li, 2020

\section{Introduction}

The concept of sustainable development of the industry includes an important part of the responsibility for the environment, in particular, the commitment to the preservation of clean air and water, narrowing down the amount of waste to the minimum. The Urals is an industrially developed region of the Russian Federation. More than 1,500 enterprises representing the mining, metallurgical, energy and other industries are found in the Urals. This neighbourhood cannot but affect the environment [1]. The Urals is one of Russia's leading regions in terms of environmental pollution [2]. It is quite an ur-

gent objective now to reduce the amount of emissions, in particular, air emissions [3]. Any type of gas-cleaning equipment has an area of optimum use. Cyclones are high-performance but are ineffective for trapping micron particles [4]. Electrofilters are effective for particles PM2.5 but are high costly $[5,6]$. Many researchers have attempted to combine two or even three types of gas cleaning devices in a single unit to improve the performance of its operation $[7,8]$. Electrocyclone is a combined dust collector that combines the centrifugal and electrostatic effects for aerosol cleaning [9]. 


\section{Experimental}

Materials, which are the products and industrial wastes of Russia's Volga and Ural regions, were chosen: 1 . Sodium percarbonate from the first and second stages of the purification of exhaust gases of the spray dryer at JSC "Percarbonate", Chuvash Republic. 2. The iron-vanadium concentrate dust released during ore annealing at JSC "Kachkanarskiy Mining and Processing Plant", Sverdlovsk region. 3. Sublimates of the blister smelting furnaces of the copper smelting shop of JSC "Sred- neuralsk Copper Plant", Sverdlovsk region. 4. The ash from the combustion of Ekibastuz coal at Reftinskaya TPP, Sverdlovsk region. The characteristics of the substances are reported in Table 1.

The main tool of the experimental equipment was a laboratory vertical electrocyclone. The diagram of it is shown in Fig. 1. An electrocyclone consists of a body 1 , snails with an inlet 2 , the central tube 3 , a corona system 4 , an exhaust pipe 5 and a hopper 6 .

\section{Results and discussion}

Figs. $2-4$ shows results of experiments. the degree of gas purification from partiIt is shown, that without an electric field, cles with a size less than 50 microns de-

Characteristics of the materials under research

Table 1

\begin{tabular}{|c|c|c|c|c|c|c|}
\hline \multirow{2}{*}{ № } & \multirow{2}{*}{ Material } & \multirow{2}{*}{$\begin{array}{l}\text { True density, } \\
\mathrm{k} / \mathrm{gm}^{3}\end{array}$} & \multirow{2}{*}{$\begin{array}{l}\text { Specific electric } \\
\text { resistance, } \mathrm{Ohm} \cdot \mathrm{m}\end{array}$} & \multicolumn{3}{|c|}{ Particle diameter, $\mu \mathrm{m}$} \\
\hline & & & & $\mathrm{d}_{10}$ & $\mathrm{~d}_{50}$ & $\mathrm{~d}_{90}$ \\
\hline 1 & Sodium percarbonate & 2144 & $<10^{4}$ & 10 & 35 & 67 \\
\hline 2 & $\begin{array}{c}\text { Iron-vanadium } \\
\text { concentrate }\end{array}$ & 5100 & $10^{3}$ & 16 & 73 & 90 \\
\hline 3 & Sublimates of furnaces & 4600 & $10^{7}$ & 2.5 & 6 & 15 \\
\hline 4 & Fly ash & 2200 & $>10^{8}$ & 15 & 32 & 64 \\
\hline
\end{tabular}

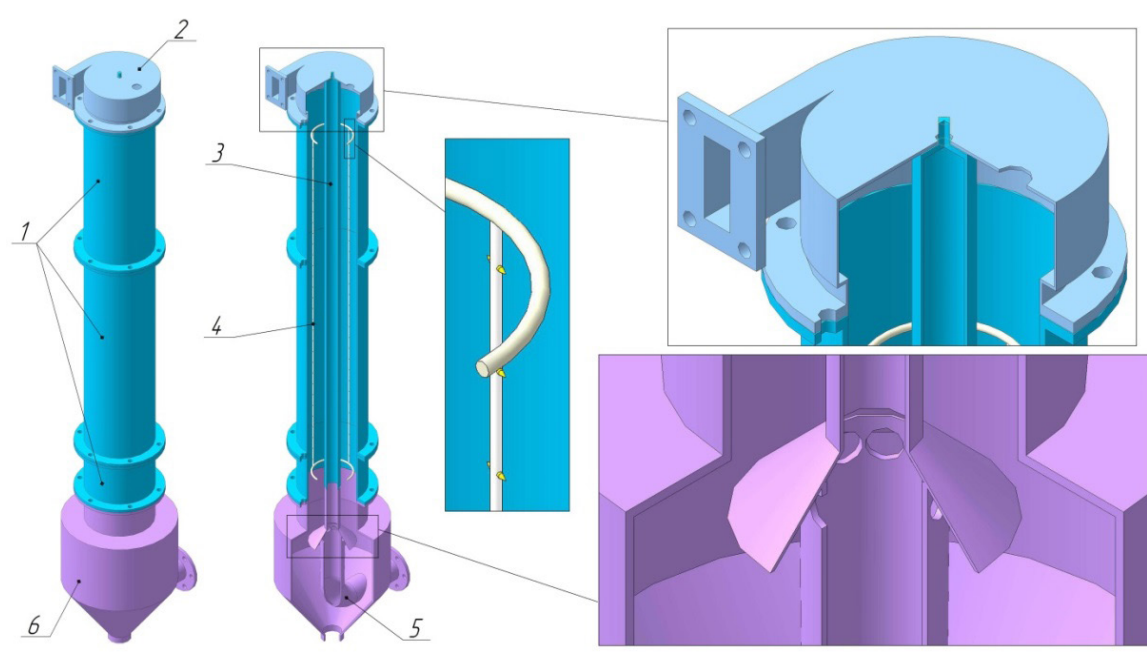

Fig. 1. Electrocyclone (model ECV) 
creases with a decrease in diameter; for micron particles it is virtually zero. When the voltage reaches $17 \mathrm{kV}$, the purification rate is higher than $90 \%$ for fine particles (less than 50 microns) in each case.
Capturing the fumes of copper-smelting furnaces electrocyclone yielded unsatisfactory results (no diagram). The degree of purification in the experiments at a voltage of $17 \mathrm{kV}$ was $50-60 \%$, and no more than $50 \%$ without voltage.

\section{Conclusions}

Studies have been held to capture is shown that an electrocyclone can be the dispersed industrial materials. It used like existing gas treatment units. For
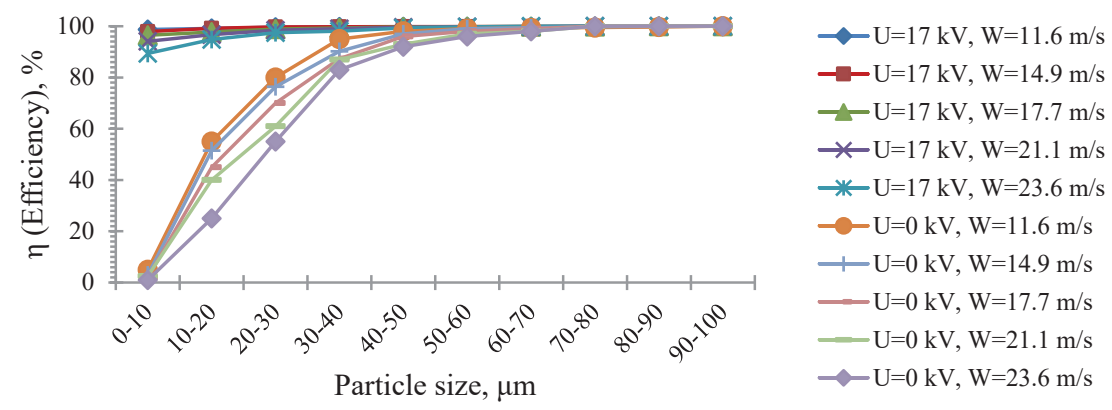

Fig. 2. Fractional efficiency (sodium percarbonate)
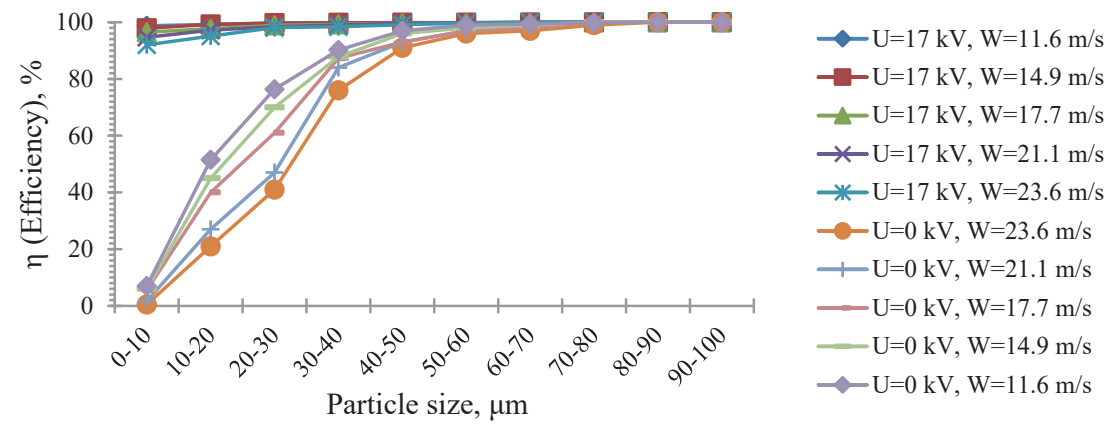

Fig. 3. Fractional efficiency (iron-vanadium concentrate)

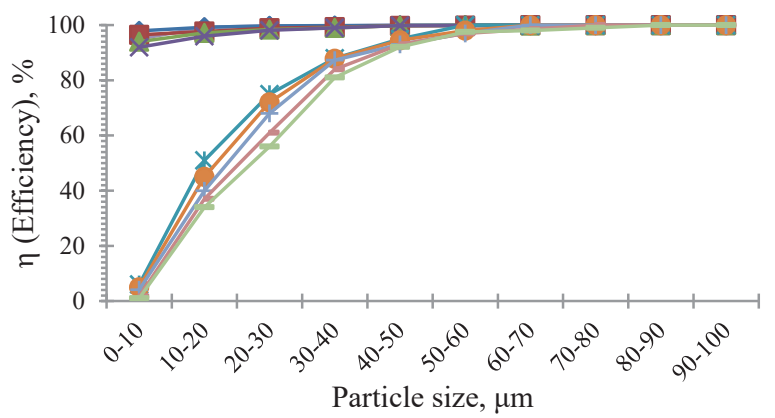

$\multimap \mathrm{U}=17 \mathrm{kV}, \mathrm{W}=11.6 \mathrm{~m} / \mathrm{s}$

$\smile \mathrm{U}=17 \mathrm{kV}, \mathrm{W}=14.9 \mathrm{~m} / \mathrm{s}$

$-\mathrm{U}=17 \mathrm{kV}, \mathrm{W}=17.7 \mathrm{~m} / \mathrm{s}$

U $=17 \mathrm{kV}, \mathrm{W}=21.1 \mathrm{~m} / \mathrm{s}$

$* \mathrm{U}=17 \mathrm{kV}, \mathrm{W}=23.6 \mathrm{~m} / \mathrm{s}$

$\rightarrow-\mathrm{U}=0 \mathrm{kV}, \mathrm{W}=11.6 \mathrm{~m} / \mathrm{s}$

$-\mathrm{U}=0 \mathrm{kV}, \mathrm{W}=14.9 \mathrm{~m} / \mathrm{s}$

$-\mathrm{U}=0 \mathrm{kV}, \mathrm{W}=17.7 \mathrm{~m} / \mathrm{s}$

$-\mathrm{U}=0 \mathrm{kV}, \mathrm{W}=21.1 \mathrm{~m} / \mathrm{s}$

$\mathrm{U}=0 \mathrm{kV}, \mathrm{W}=23.6 \mathrm{~m} / \mathrm{s}$

Fig. 4. Fractional efficiency (fly ash) 
example, in catching sodium percarbonate, the efficiency reached $97.5-99.9 \%$. The iron-vanadium concentrate collection efficiency was up to $98-99.9 \%$. The ash of TPP can be caught with an efficiency up to $99.9 \%$. The optimum operating flow rate of aerosol at the inlet to electrocyclone lies in the range $15-17 \mathrm{~m} / \mathrm{s}$. In capturing the fumes of the copper-smelting furnaces some satisfactory data were received (the efficiency does not exceed 50-60\%).
This can be explained by the high dispersion and adhesion. The factors have led to the termination of electrical purification. In general, the electrocyclone can reduce aerosol emissions from industrial plants into the atmosphere by a few digits to several tens of times. In each case, before choosing an electrocyclone as a gas treatment unit, individual characteristics of the material should be evaluated.

\section{References}

1. Bréchignac F, Desmet G. Equidosimetry: Ecological Standardization and Equidosimetry for Radioecology and Environmental Ecology. Springer Science \& Business Media; 2005. 436 p.

2. Linkov I, Wilson R. Air Pollution in the Ural Mountains: Environmental, Health and Policy Aspects. Springer Science \& Business Media; 2012. 455 p.

3. Gafurova S. Ecological problems of trans-Ural zone come out to the forefront [Internet]. 2011- [updated 2011.02.17; cited 2020.10.12] http://www.bashinform.ru/eng/341343/.

4. Ng SY, Priestman GH, Allen RWK. Investigation of Flooding, Re-Entrainment and Grade Efficiency in Axial Flow Cyclones. Chemical Engineering Research and Design. 2006;84:884-94. doi:10.1205/cherd05063

5. Sudrajad A, Yusof AF. Review of Electrostatic Precipitator Device for Reduce of Diesel Engine Particulate Matter. Energy Procedia. 2015;68:370-80. doi:10.1016/j.egypro.2015.03.268

6. Ait Said H, Nouri H, Zebboudj Y. Effect of air flow on corona discharge in wire-toplate electrostatic precipitator. Journal of Electrostatics. 2015;73:19-25. doi:10.1016/j.elstat.2014.10.004

7. Krames J, Büttner H, Ebert F. Particle separation in a wet operated cyclone. Journal of Aerosol Science. 1993;24:S591-2. doi:10.1016/0021-8502(93)90388-P

8. Di Natale F, Carotenuto C, D’Addio L, Jaworek A, Krupa A, Szudyga M et al. Capture of fine and ultrafine particles in a wet electrostatic scrubber. Journal of Environmental Chemical Engineering. 2015;3:349-56. doi:10.1016/j.jece.2014.11.007

9. Titov AG, Shrimpton J. 3D Modeling of Electrocyclones with Various Flow Swirling Devices. Chemical and Petroleum Engineering. 2020;55:876-83. doi:10.1007/s10556-020-00707-w 